\title{
Dr. Aníbal Julio Acuña
} ¡Adiós Aníbal!

$\mathrm{E}^{1}$ 17 de mayo de 2021, un viernes de Pandemia, me encuentro leyendo en el grupo Whatsapp de Residentes, la noticia del fallecimiento del Coronel Médico Aníbal Julio ACUÑA, apodado por sus amigos "el Monje", por lo alto, delgado, con la palabra adecuada y su sonrisa franca, hombre sin maldad. Todos los traumatólogos sentimos una enorme congoja por la temprana

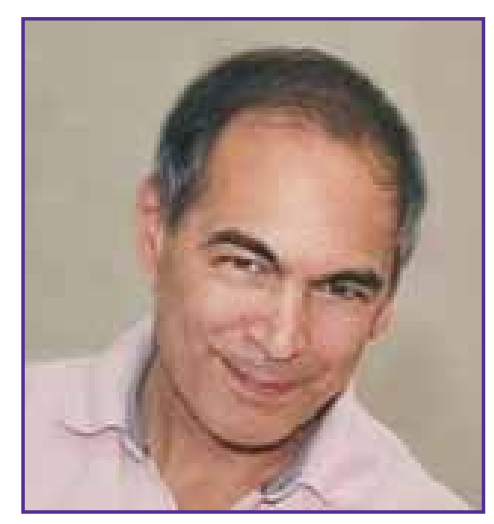
muerte de un colega fuera de serie. Queda trunca una gran expectativa por sus grandes cualidades médicas. Destacado por su razonamiento y sagacidad para resolver los más complicados planteos clínico-quirúrgicos, de memoria prodigiosa, respaldada en el manejo multimedia, por momentos original, creador y artista. Nacido el 3 de julio de 1968, en Córdoba, hijo mayor de seis hermanos, destaco uno de ellos, su agraciada hermana. Se mudaron a Salta en donde su padre médico ejerció nuestra profesión como anestesista. Ya graduado ingresó a la Sanidad Militar con el grado de Teniente Primero Médico Residente de Traumatología y Ortopedia, siendo dado de alta el 31 de diciembre de 1992. Primero de su camada, sus compañeros fueron Maxi RODRIGUEZ, Marcelo COTARELO, Pablo RUIZ, Roberto CASTELLI, Fernando GALLO. Cursaron la residencia con dos colegas médicos civiles Gustavo CAPURRO y Víctor DÍAZ MARTINEZ, colombiano. Su Jefe de Residentes e instructor, porque ya era de planta, el entonces Capitán Médico Carlos Eugenio MARTINEZ. Recordemos que, en el Hospital Militar Central, existían en ese momento dos equipos bien caracterizados, representados por dos prestigiosos especialistas, los doctores Carlos Manuel Osvaldo VILARIÑO y Ariel Darío BARRERA ORO. Un Servicio de Cirugía de la Mano, creado por el Dr. León A. POCHAT en el 1954, apartado del resto del Departamento, presidido en su pasaje por el hospital, por el que escribe, quien se permite estas consideraciones para interpretar al hombre y sus circunstancias.

En 1995, el Dr. Aníbal Julio ACUÑA tuvo su primera misión en el extranjero, UNPROFOR CROACIA, ex Yugoslavia, en donde tiene su Bautismo de Fuego el 31 de mayo, participó durante la ofensiva del Ejército Serbio. Integró la sección Sanidad de la Ca A, que rescataran las secciones aferradas en diversas posiciones. Integró la misión "pasaje seguro" de población civil a zonas fuera de conflicto. Todas las operaciones fueron con riesgo de vida, recibiendo la Condecoración UNPROFOR. Su segunda misión fue en 1998 por la ONU UNFICYP, en el conflicto bélico entre GRECIA y TURQUÍA en la Isla de Chipre. En donde fuera el primer SMO (Senior Medical Officer) de la UNPA (United Nation Protection Area). Allí también recibió condecoración. En el 1997 entra en el Servicio de Cirugía de la Mano del Hospital Militar Central, que ya contaba con el Dr. Fredy Aponte Arrazola, en calidad de consultor. Demostrando su especial interés por la especialidad cursando en forma paralela, con el Dr. Carlos ZAIDENBERG, quien lo apodaba "el soldado", con quien estuviera perfeccionando sus conocimientos por espacio de un año. En esa oportunidad, entabló una férrea amistad con el Dr. Álvaro Muratore, actual Presidente de la Asociación Argentina de Cirugía de la Mano. En el 2000, se casa en Salta con Luciana, con quien tiene cuatro hijos, Máximo 18, Augusto 17, Victoria 14 y Octavio 11. En el 2003 fue nombrado Jefe del Servicio de Cirugía de la Mano del Hospital Militar Central, tiempo en el cual presenta destacados trabajos, hasta llegar a ser miembro titular, luego de haber trabajado en varias comisiones. En el 2006, por sus condiciones de liderazgo es nombrado Jefe de Traumatología y Ortopedia del Hospital Militar Campo de Mayo, siguiendo su carrera hasta la fecha, en los diversos puestos de creciente jerarquía, hasta llegar a ser el Director del Hospital Militar Campo de Mayo. Debo destacar que nunca dejó su actividad docente para la UBA y para la Universidad Barceló... El domingo 9 de mayo lo fuimos a despedir en el Cementerio de la Chacarita con todos los honores militares, acompañado siempre por Denise, sus hijos, toda su familia, colegas y amigos. En lo personal es muy triste vivir la pérdida de un colega más joven, no es natural despedir a quien iniciara sus primeros años en la especialidad. Muchos de los nombrados se expresan a través de mis palabras. ¡iiAdiós Aníbal !!!... siempre estarás entre nosotros.

Dr. ALEJANDRO J. RAMOS VÉRTIZ • ramvertiz@fibertel.com.ar

https://orcid.org/0000-0001-9836-2314

Cómo citar este artículo: Ramos Vértiz AJ. Obituario. Dr. Aníbal Julio Acuña. iAdiós Aníbal! Rev Asoc Argent Ortop Traumato/ 2021;86(3):442. https://doi.org/10.15417/issn. 1852-7434.2021.86.3.1375 